\title{
A Study on Cultural Adaptation By Using Social Media Among Indonesian And Malaysian Students
}

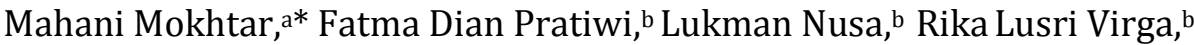 \\ Diah Ajeng Purwani, b Niken Puspitasari, b and Yusof Boon ${ }^{\mathrm{a}}$ \\ ${ }^{a}$ Faculty of Education, Universiti Teknologi Malaysia \\ ${ }^{b}$ Department of Communication Science Universiti Islam Negeri Sunan Kalijaga Yogyakarta
}

\begin{abstract}
This paper discusses the emergence of new media in the process of intercultural adaptation and it is based on a study which investigated how Indonesian and Malaysian students used social media in order to gain successful cultural adaptation. Cultural adaptation involves the process of promoting understanding through interaction to increase the level of fitness so that the demands of a new cultural environment can be met. Data of the study were gathered through in depth interview with five Indonesian students who were studying in Malaysia and also five Malaysian Students who were studying in Indonesia. The findings of this study showed that Malaysian and Indonesian students used social media especially You Tube channel in order to get information about the culture of the countries which they were studying at.
\end{abstract}

Keywords: Cultural Adaptation, Social Media, Indonesian and Malaysian Students

\section{INTRODUCTION}

In the age of globalization, it is common for people to go abroad to continue their studies. For example, Indonesian citizens who choose to study in Malaysia, or vice versa. While studying, they have to undergo the process of cultural adaptation, since it will be one of the vital factors to survive. Therefore, it is interesting to explore their journey and whether social media is used in the adaptation process.

Studies have indicated that social media is useful in helping students adapt with the new cultural environment since it provides the context to communicate, interact and even share knowledge. According to Chen and Zhang, "The compression of time and space, due to the convergence of new media and globalization, has shrunk the world into a much smaller interactive field."

Therefore, during cultural adaptation, students who study abroad use social media to study the culture of the hosts' countries, to interact, to find some new friends as well as to stay inform about the activities of their home countries, and to keep in touch with their friends, whether they are in the host or home country.

This paper will present findings from a study which investigated how Indonesian and Malaysian students went through cultural adaptation with the help of social media and also identified the stage which the students belonged to.

\subsection{Social Media}

Difficulties seem to be encountered when the concept of mass media which is approved by various researchers is questioned. However, a common thread about the concept of mass media may be drawn from where it can be understood as an institution or organization which is engaged in the dissemination of information to a wide audience where the process of disseminating information is a mass communication activity ${ }^{2}$.

*p-mahani@utm.my
This concept is usually used to designate institutions such as newspapers, television, radio and later the internet.

\subsection{Media Access}

Access media in this research can be described as the wide diffusion of the Internet to the public. It is clear that full access to the new communication technologies implied more than just about 'network connectivity', 'accessibility of hardware' and other technical considerations that are too often become the focus of policy discussions. Newhagen as observed in a dialogue with Rafaeli ${ }^{3}$ said, "Net users are involved in cognitive tasks that effortful and challenge them to actively interact" as is the case with the mass media. It is important to ask what will impact the human skills variables, such as the ability to process content or search cognitive, on the ability to feat the potential of the Internet. Moreover, what kind of social factors and culture that can hinder the adoption of new technologies and uses, especially in disadvantaged communities. The access problem, then, is not only depend on the educational background and the economy, but also on their characteristics of the social, cultural, and psychological.

\subsection{Intercultural Adaptation}

There are four stages of intercultural adaptation, which is important to describe its connection to the media use. The four stages are honeymoon, crisis, adjustment, and biculturalism ${ }^{4}$. The first stage is the honeymoon stage. During this phase, people are experiencing fresh euphoria on getting touch with new different culture, in this case with the different culture in a different country. The second stage is crisis stage. It consists of the hostility and frustation with living in an unfamiliar area and culture. However, this stage will be reduced gradually. There will be a process of adjustment and recovery which makes people become fully adjusted and become biculturalism which is the fourth stage. 
The four stages of cultural adaptation will be hard to be reached due to culture shock which can happen inside people's mind. According to Kohls, ${ }^{5}$ culture shock is the "psychological disorientation most people experience when they move for an extended period of time into a culture different from their own." At certain level, everyone will be experiencing the culture shock. Culture shock itself is a distress which everyone feels during intercultural adaptation that can influence how they communicate and behave with the environment of new culture that they want to adapt. Communication will be the most important feature in this intercultural process.

Communication process stated above will be eminent solution in order to minimalize the effect of culture shock. Talking with others before and after is beneficial in order to get as much knowledge as possible about the host culture. This effort will influence their adjustment process which is related to their emotions. Consequently, the emotion that is controlled will affect their ability to engage in the learning and understanding process. "Only through global communication competence can people from different cultures communicate effectively and productively in the globalizing society ${ }^{6}$ " The competency of global communication is an important ability in order to develop the understanding of other culture and communicate successfully.

The competence stated above involves cognitive, effective, and behavioral aspects. In addition, it is the ability to possess global mindset, unfold the self, map the culture, and align the interaction $^{7}$. The first competence is having global mindset. It involves the broadening process of one's perspectives in order to open their mind to different ways of life. The second one is unfolding the self. "Unfolding the self is a process of transforming and moving oneself from the lower to higher level of the developmental ladder of human beings ${ }^{7}$ ". The empathy that is incorporated in this dimension influences the development of sensitivity and creativity. These traits encourage learning and increase global communication competence. The third competence is mapping the culture. Mapping the culture is important in order to compare the original culture the new one. Lastly, aligning the interaction contributes to the ultimate goal of successfully interacting and demonstrating cultural adroitness, the ability of interactants to execute communication behaviors to elicit desired responses in a global communication environment without violating their counterparts' norms and rules ${ }^{7}$.

The new wave of technology development has made internet to become the most popular media. Subsequently, everyone can be easily connected with the others not only family and friends in their native countries but also with the locals in the host countries. In an online environment, the host social communication and the ethnic social communication are important components that can facilitate or impede adaptation ${ }^{8}$. Therefore, this study examined how Internet usage of social media sites impacted the adaptation process for international students both in Indonesia and Malaysia.

\section{METHODOLOGY}

Qualitative method using descriptive analytic study approach was used in this study, as expressed ${ }^{9}$ is a method to obtain data which is deep and contain meaning. Qualitative description is a label used in qualitative research for studies that are descriptive in nature. With these studies, researchers can examine factors which may influence behavior. The study adopted qualitative research analysis using three paths of qualitative data analysis according to Miles and Huberman in Sitorus. ${ }^{10}$ :
1. Data reduction is the selection process, focusing on simplification, abstraction and data transformation.

2. Data display is the display of data that has been reduced and compile data in order to help the conclusion.

3. Conclusion Drawing and Verification involve stepping back to consider what the analyzed data mean and to assess their implications for the questions at hand. While verification, integrally linked to conclusion drawing, entail revisiting the data as many times as necessary to crosscheck or verify these emergent conclusions.

\section{RESULTS}

\subsection{Sosial Media Usage}

Talking about the uses of social media, majority of the respondences had a high degree of social media usage. The responses indicated that they used social media, such as facebook, Instagram, Youtube, Whatsapp and Twitter.

“Yes, one or two times a day Q1"(interviewee 2)

"As a media to get information and entertainment. I never really involved with any social media site Q2" (interviewee 2)

"Yes, it helped me making Malaysian and non-Malaysian friends" Q6 (interviewee 6)

How often? "Quite often, when there is no work to do". How much time? “ Never counted." Q1 (interviewee 2)

"Getting and sharing information, communication." Q2 (interviewee 2)

"Yes, because I got most of update situation and can maintain my relationship with the other" Q8 (interviewee 2)

"Advantages: a lot of information, getting know with each other and maintaining a friendship. Disadvantages: some information in social media are hoax and social media tend to be used as "mass weapon" to the other." $\mathrm{Q} 9$ (interviewee 2)

Do you use social media? "Using facebook, youtube, instagram, line, whatsapp. Whatsapp and Line I use everyday to chat with friends but youtube, facebook and instagram are not sure of their usage." How often? "Facebook and Instagram only when there is no busyness. Often to broadcast after a picnic. A week is only 2 to 3 times. For youtube often to learn makeup and hijab, and even then not often." Q1 (Interviewee 5)

"Yes, I use instagram to search for places I've been looking for in google. Especially the bookie where my college in Indonesia. I used to search on google, about events that are often held in the city where the lecture. From these shows, it gives me a bit of an overview of the culture in Indonesia." Q3 (interviewee 5)

\subsection{The Four Stages of Cultural Adaptation}

Data on the use of social media and intercultural adaptation showed that the interviewees shared similliar responses. The presentation of results is supported by direct quotations from their answers and directly analyzed using the four stages of 
cultural adaptation concept ${ }^{6}$ and the competency of global communication $^{7}$ The interview responses indicated that they went through only two stages of cultural adaptation namely; honeymoon and biculturalism stages. The following responses showed how they were classified into those two stages.

\section{a. Honeymoon stage}

During this stage, people are experiencing the fresh euphoria on getting in touch with new different culture. The responses showed that the students were excited to get information about the new culture from social media.

"Yes of course. excited on new culture .with my friend.i learn a lot about indonesia people with their kindness and i learn about their food and nature, history place." Q3 (interviewee 1)

"I feel satisfied because social media help me very fast when $i$ need to find something at anywhere. "Q8 (interviewee 2)

"Social media can contribute in terms of broadly introducing the culture, life and practice of the nation using famous websites to all countries of world." (interviewee 3\#)

"Yes, I am satisfied. Information can be accessed very easily. Not to mention I can post about my experiences in Indonesia so my friends in malaysia know." (interviewee 5)

\section{b. Biculturalism stage}

At this stage, people usually become fully adjusted with their new culture. People who have reached this stage usually have lived long enough on the new area. Interaction and negotiation between indigenous cultures and new cultures have already been experienced.

"In Malaysia, particularly within the platform of social media, I used Malay to communicate with Malaysians fellow (particulary with Bumiputera and Indian Malaysian). I think it may builds more trust. Based of this trust, it may gives more opportunities to blend with Malaysian community. Meanwhile, I used Bahasa and Acehnese language (as I am Acehnese) to communicate with someone I know from my hometown. And the effect is quite similar with above." (interviewee 3)

"Somehow, social media is bridging the sense of togetherness." (interviewee 2)

"Yes, it helped me making Malaysian and non-Malaysian friends expecially with my neighbours." (interviewee 6).

\section{DISCUSSION}

Social media sites such as Instagram and Youtube are very influential in the process of cultural adaptation. They are used especially for getting information about the host countries and getting new friends.

Majority of the Indonesian respondents came to Malaysia for a short visit (under 1 year) and eventually they were just in the honeymoon stage. In contrast, respondents who had a stopover time of more than 1 year experienced the stage of biculturalism. Majority of respondents possessed global mindset since they were willing to open themselves to the new culture. The process was easy due to vast similarity between Indonesian and Malaysian culture. Simultaneously, the process of unfolding the self seemed to be helped by the use of social media. Social media was used by majority of the respondents to get information about the culture of the host country. The data proved that the process of culture mapping was smooth since their local culture is not too much different from the culture of the host country.

\section{References and Notes}

1. G. M Cheng and K. Zhang, New Media and Cultural Identity in the Global Society, In $\mathrm{R}$. Taiwo(Ed.) Handbook of Research on Discourse Behavior and Digital Communication : Language Structures and Social Interaction (pp.801-815). Hersley, PA : Idea Group Inc (2010).

2. Mufid Muhamad, Komunikasi dan Regulasi Penyiaran. Jakarta: Kencana (2007).

3. E. P Bucy, Second Generation Net News: Interactivity and Information Accessibility in the Online Environment. IJMM: The International Journal on Media Management, 6(1\&2), 102-113 (2004).

4. G. M Chen, G. M, and W. J Starosta, Foundations of intercultural communication. Lanham, MD: University Press of America (2005).

5. L. R Kohls, Survival Kit for Overseas Living. Yarmouth, ME: Intercultural Press (2001).

6. G. M Chen and W. J Starosta, Intercultural Communication Competence: A Synthesis Communication Competence: A synthesis Communication Yearbook, 19, 353-384 (1996).

7. G. M Chen, A Model of Global Communication Competence. China Media Research, 1, 3-11 (2005).

8. W. Chen, Internet Use and Intercultural Adaptation: A Case Study on Chibese Immigrants in Singapore. Paper presented at the Annual Meeting of the International Communication Association, New York City, NY (2009).

9. Sugiyono, Metod Penelitian Kuantitatif Kualitatif dan $R \& D$. Alfabeta, (2012).

10. Sitorus Felix. Penelitian Kualitatif Suatu Pengantar, Bogor, kelompok dokumentasi IImu sosial (1998). 